\title{
Utilization of Recycled Concrete Aggregates in Stone Mastic Asphalt Mixtures
}

\author{
Mohammad Saeed Pourtahmasb and Mohamed Rehan Karim \\ Center for Transportation Research (CTR), Department of Civil Engineering, Faculty of Engineering, \\ University of Malaya (UM), 50603 Kuala Lumpur, Malaysia \\ Correspondence should be addressed to Mohammad Saeed Pourtahmasb; sp.um.eng@gmail.com
}

Received 1 October 2014; Revised 26 November 2014; Accepted 28 November 2014; Published 17 December 2014

Academic Editor: You Song

Copyright (C) 2014 M. S. Pourtahmasb and M. R. Karim. This is an open access article distributed under the Creative Commons Attribution License, which permits unrestricted use, distribution, and reproduction in any medium, provided the original work is properly cited.

\begin{abstract}
Recycled concrete aggregate (RCA) is considered as one of the largest wastes in the entire world which is produced by demolishing concrete structures such as buildings, bridges, and dams. It is the intention of scientists and researchers, as well as people in authority, to explore waste material recycling for environmental and economic advantages. The current paper presents an experimental research on the feasibility of reusing RCA in stone mastic asphalt (SMA) mixtures as a partial replacement of coarse and fine aggregates. The engineering properties of SMA mixtures containing RCA have been evaluated for different percentages of binders based on the Marshall mix design method. The outcomes were statistically analyzed using two-factor analysis of variance (ANOVA). Test results revealed that the performance of SMA mixtures is affected by RCA due to higher porosity and absorption of RCA in comparison with virgin granite aggregates. However, the engineering properties of SMA mixtures containing a particular amount of RCA showed the acceptable trends and could satisfy the standard requirements. Moreover, to achieve desirable performance characteristics, more caution should be made on properties of SMA mixtures containing RCA.
\end{abstract}

\section{Introduction}

In recent years, natural resources have been considerably reduced due to growth of mining industries and increase in the usage of mined materials [1]. Aggregate is a mined material which is being used in civil structures such as buildings, dams, bridges, and pavements. The amount of aggregate in asphalt paving mixtures is generally 90 to 95 percent by weight or 75 to 85 percent by volume and almost 12500 tons of aggregates are being consumed for each kilometer of flexible pavements [2]. These amounts of aggregates are mostly produced from natural recourses. Environmental and economic advantages have encouraged civil engineers to reuse recycled materials in new constructions [3]. Recent studies indicated that recycled concrete aggregate (RCA) materials have been used successfully in new concrete constructions as structural or nonstructural purposes [4-8]. Also, several studies have been carried out on the possibility of using RCA in base and subbase either as unbound materials or bitumen-treated or cement-treated granular materials [9-11]. Poon and Chan
[12] investigated the usage of RCA and mixture of bricks and RCA on the load-bearing and compression capacity of road subbase. Test results showed the CBR values higher than $30 \%$, which could prove the capability of these materials to be used in subbase. RCAs have different physical, chemical, and mechanical properties compared to natural aggregates due to the cement paste that is attached to the surface of the recycled aggregates. This cement paste causes RCAs to have a lower density, greater water absorption, and a lower abrasion resistance [13-15]. The possibility of using RCA as a partial aggregate substitution in hot mix asphalt (HMA) mixtures was investigated by Wong et al. [13]. Virgin granite aggregates with $6 \%$ untreated, $45 \%$ untreated, and $45 \%$ heattreated RCA were mixed to produce HMA mixtures based on the Marshall mix design method. All the mixtures could fulfill the minimum requirements of the Singapore land transport authority. The mixture containing higher amounts of RCA showed higher resilient modulus values and creep resistance compared to control mixtures. A research on the feasibility of using RCA for a low-volume traffic road in Michigan was 
carried out by Mills-Beale and You [14]. 25\%, 35\%, 50\%, and $75 \%$ of virgin aggregates by weight of total aggregates substituted with RCA. It was found that the HMA mixtures containing RCA needed lower energy for compaction compare to control mixtures. However, increasing the percentage of RCA decreased the VMA and VFA values of the mixtures. All the HMA mixtures containing RCA could fulfill the minimum rutting requirements in terms of rut depth values. In terms of moisture induced damage test, all the mixtures except $75 \%$ RCA mixture passed the tensile strength ratio of $80 \%$. Also, dynamic modulus test results indicated that the level of stiffness of mixtures containing RCA was less than control mixtures. In another experiment, the influence of RCA as a coarse aggregate in HMA mixtures was performed by Paranavithana and Mohajerani [15]. Coarse RCA was used as fifty percent (by dry weight) of the total aggregates in the HMA mixtures. The results indicated that using RCA in HMA increased the potential of HMA mixtures to stripping. In addition, the resilient modulus and creep resistance values of the HMA mixtures containing RCA have been reported lower than the control mixture. Arabani et al. [16] presented the reuse of recycled waste concrete in hot mix asphalt as a partial or total replacement of coarse aggregate (CA), fine aggregate (FA), and filler to evaluate the performance of HMA specimens containing RCA materials. Test results revealed that the optimum formulation was a mixture of deceit CA and RCA-FA which performed better results compared to other mixtures in terms of Marshall stability (MS), fatigue, permanent deformation (rutting), and resilient modulus tests. Arabani and Azarhoosh [17] determined the mechanical properties of asphalt mixtures containing steel slag and waste concrete aggregates. Mechanical properties of the asphalt specimens were evaluated by Marshal stability, indirect tensile resilient modulus, dynamic creep, and indirect tensile fatigue tests. Test results indicated that using steel slag as coarse aggregate and waste concrete as fine aggregate was the optimal. Influence of demolition waste (DW) on the performance of asphalt mixture was investigated by $\mathrm{Wu}$ et al. [18]. In this study, Demolished wastes (DW) were divided into two groups based on the particular size of the aggregates. Coarse recycled aggregates with a particle size of $>4.75 \mathrm{~mm}$ and recycled aggregate fines with a particle size of $\leq 4.75 \mathrm{~mm}$. Three mixtures were prepared, including DW fine and coarse limestone aggregates, DW coarse and fine limestone aggregates, and the control mixture containing $100 \%$ limestone aggregates. Scanning electron microscopy, immersion Marshall, freeze-thaw split, bending test at low temperature, and rutting test at high temperature were applied to determine the performance of the asphalt mixtures. Performance tests showed satisfactory results and could fulfill China's technical specifications. In another study, the possibility of using precoated RCA for hot mix asphalt was evaluated. $0.25,0.45$, and $0.65 \mathrm{~mm}$ of slag cement paste was used to coat the recycled concrete aggregates. Test results showed that the thickness of $0.25 \mathrm{~mm}$ had the optimum coating paste volume for HMA. The moisture induced damage, rutting, and indirect tensile strength tests were carried out to evaluate the performance of HMA specimen with substitution ratios of $25 \%, 50 \%, 75 \%$, and $100 \%$ precoated
RCA. Test results indicated that the properties of HMA specimens containing precoated RCA were comparable to conventional HMA mixtures [19].

Utilization of recycled concrete aggregates as a total replacement of virgin granite aggregate in porous asphalt mixtures was investigated by Chen and Wong [20]. In this research, Draindown, Cantabro, Marshal, permeability, and ageing tests were carried out to evaluate the performance of the porous asphalt mixtures. Test results indicated that the modified porous asphalt mixtures containing 100\% recycled concrete aggregates could adequately fulfill the Marshall criteria of Singapore's Land Transport Authority Standard stipulated for normal roads. The effect of ageing time on properties of hot mix asphalt containing recycled concrete aggregates was presented by Pasandín and Pérez [21]. Hot mix asphalt (HMA) mixtures containing 0\%, 5\%, 10\%, 20\%, and $30 \%$ RCA were placed in an oven for $0 \mathrm{~h}, 2 \mathrm{~h}$, and $4 \mathrm{~h}$ at the mixing temperature prior to compaction. Permanent deformation (rutting), stiffness, and volumetric tests were applied to the asphalt specimens. The results showed that increasing the ageing time increased the number of air voids, the stiffness at ambient temperature, and the initial permanent deformation of the HMA mixtures containing RCA. In another experimental research, the rutting susceptibility of asphalt mixtures containing RCA has been investigated [22]. $0 \%, 25 \%, 50 \%$, and $75 \%$ of the virgin limestone aggregates were replaced with RCA. Revised Marshall mix design method was used for sample preparation and the permanent deformation (rutting) of the asphalt mixtures containing RCA has been measured by using repeated creep test. Test results indicated that effect of aggregate gradation is more significant than that of RCA content. Also, increasing the RCA content in coarse graded asphalt mixtures increased permanent deformation resistance of the asphalt mixtures. The possibility of utilizing construction and demolition (C\&D) waste as coarse aggregate in HMA mixtures was evaluated by Pérez et al. [23]. 0\%, 20\%, 40\%, and $60 \%$ of the virgin limestone coarse aggregates were replaced with C\&D wastes. Cement and lime powder were used as fillers. Based on the obtained results from the wheel tracking test, the HMA mixtures containing RCA showed good resistance to permanent deformation. However, the stripping test results showed lower durability in the HMA mixtures containing RCA due to high susceptibility to water.

The application of RCA in HMA base layer was carried out by Cho et al. [24]. Four types of aggregate blends were used to produce the HMA mixtures based on the Superpave mix design method. Test results revealed that all the mixtures performed the satisfactory results in terms of the indirect tensile strength ratio, deformation strength, rut depth, and IDT strength except the HMA specimens containing 100\% of coarse and fine RCA. It was also concluded that the dynamic loading of Marshall compactor causes friction in the mixtures containing RCA and leads to an underestimation of the engineering properties. Xuan et al. [25] studied on the mechanical properties of RCA with laboratory cement treatment. Test results indicated that the mechanical properties of the cement treated granular materials (CTGM) made with recycled aggregates were highly dependent on the cement 
TABLE 1: Gradation used in this study (SMA 20).

\begin{tabular}{lcccc}
\hline $\begin{array}{l}\text { Sieve size } \\
(\mathrm{mm})\end{array}$ & $\begin{array}{c}\text { Upper } \\
\text { limit }(\%)\end{array}$ & $\begin{array}{c}\text { Lower } \\
\text { limit }(\%)\end{array}$ & $\begin{array}{c}\text { Desired } \\
\text { passing }(\%)\end{array}$ & $\begin{array}{c}\text { Desired } \\
\text { retain }(\%)\end{array}$ \\
\hline 19 & 100 & 100 & 100 & 0 \\
12.5 & 95 & 85 & 90 & 10 \\
9.5 & 75 & 20 & 70 & 20 \\
4.75 & 28 & 20 & 24 & 46 \\
2.36 & 24 & 16 & 20 & 4 \\
0.6 & 16 & 12 & 14 & 6 \\
0.3 & 15 & 12 & 13 & 1 \\
0.075 & 10 & 10 & 10 & 3 \\
Filler & - & - & - & 10 \\
\hline Total & & & & $100 \%$ \\
\hline
\end{tabular}

type and content. However, curing time, quantity of water, and quality of the RCA were the other effective factors on the performance of CTGM. It was concluded that using RCA as a partial replacement of virgin aggregates perform satisfactory in HMA mixtures. However, the performance of the HMA was highly affected by percentage of fine RCAs due to higher water absorption in comparison with virgin aggregates. Therefore, using fine RCA should not exceed 30 percent in the asphalt mixtures.

\section{Materials and Methods}

2.1. Materials. The materials that have been used for this research were recycled concrete aggregates (RCA), hydrated limestone powder (filler), granite aggregates, $80 / 100$ penetration grade binder, and oil palm fibers. The crushed granite aggregates were provided from Kajang rock quarry (located near Kuala Lumpur, the Malaysian capital). To provide the RCA, concrete beams were crushed into large chunks and the steel bars were subsequently removed. Finally, the crusher machine was used to crush the concrete debris and produce the proper sized aggregates. The rest of the materials were provided by university materials supplier. In this study, SMA 20 was used as a preferred gradation to produce the asphalt specimens based on the Asphalt Institute (AI) criterion. The employed aggregate gradation is presented in Table 1. Also, the properties of the employed aggregates, RCA and 80/100 binder are, respectively, tabulated in Tables 2 and 3.

2.2. Sample Preparations. In this paper, the Marshall mix design method was used for the fabrication of SMA specimens. Five different percentages of RCA (0\%, 20\%, $40 \%$, $60 \%$, and $80 \%)$ were blended with virgin granite as a partial replacement of RCA (coarse and fine) by virgin granite aggregates (by the total weight of the aggregates in the mixture) to produce SMA specimens. Also, the SMA specimen containing $0 \%$ RCA (100\% virgin aggregates) was performed as control mix. Note that, based on the previous experiment [26], to reduce the excessive amount of dusts and cements from the surface of the crushed concretes and increase the adhesion between crushed concretes and other materials,
TABLE 2: Properties of aggregates.

\begin{tabular}{|c|c|c|c|c|}
\hline Test & Method & Granite & RCA & $\begin{array}{c}\text { Standard } \\
\text { requirement }\end{array}$ \\
\hline LA abrasion (\%) & ASTM C131 & 18.3 & 24.5 & Below 30\% \\
\hline $\begin{array}{l}\text { Aggregate impact } \\
\text { value (\%) }\end{array}$ & BS812: Part 3 & 6.21 & 11.3 & Below 15\% \\
\hline $\begin{array}{l}\text { Aggregate crushing } \\
\text { value }(\%)\end{array}$ & BS812: Part 3 & 20.8 & 28.3 & Below 30\% \\
\hline $\begin{array}{l}\text { Flakiness index } \\
(\%)\end{array}$ & BS812: Part 3 & 7.90 & 9.80 & Below 20\% \\
\hline Angularity number & BS812: Part 3 & 6.31 & 8.40 & $\begin{array}{c}\text { Between } 6 \text { to } \\
9\end{array}$ \\
\hline $\begin{array}{l}\text { Elongation index } \\
(\%)\end{array}$ & BS812: Part 3 & 8.10 & 5.35 & Below 20\% \\
\hline $\begin{array}{l}\text { Polished stone } \\
\text { value }(\%)\end{array}$ & BS812: Part 3 & 50.7 & 57.3 & Above $40 \%$ \\
\hline $\begin{array}{l}\text { Specific gravity of } \\
\text { coarse aggregates } \\
(\%)\end{array}$ & $\begin{array}{l}\text { ASTM C } \\
127-07\end{array}$ & 2.61 & 2.18 & - \\
\hline $\begin{array}{l}\text { Specific gravity of } \\
\text { fine aggregates }(\%)\end{array}$ & $\begin{array}{l}\text { ASTM C } \\
128-07\end{array}$ & 2.64 & 2.42 & - \\
\hline $\begin{array}{l}\text { Water absorption } \\
\text { of coarse } \\
\text { aggregates (\%) }\end{array}$ & $\begin{array}{l}\text { ASTM C } \\
127-07\end{array}$ & 0.44 & 2.69 & - \\
\hline $\begin{array}{l}\text { Water absorption } \\
\text { of fine aggregates } \\
(\%)\end{array}$ & $\begin{array}{l}\text { ASTM C } \\
128-07\end{array}$ & 1.11 & 4.28 & - \\
\hline
\end{tabular}

TABLE 3: 80/100 binder test results.

\begin{tabular}{lccc}
\hline Test & Method & Value & $\begin{array}{c}\text { Standard } \\
\text { requirement }\end{array}$ \\
\hline $\begin{array}{l}\text { Penetration @ } \\
25^{\circ} \mathrm{C}(0.1 \mathrm{~mm})\end{array}$ & ASTM D5 & 84.7 & $84-95$ \\
$\begin{array}{l}\text { Softening point } \\
\left({ }^{\circ} \mathrm{C}\right)\end{array}$ & ASTM D36 & 47.2 & $47-49$ \\
Flash point $\left({ }^{\circ} \mathrm{C}\right)$ & ASTM D92 & 289 & $275-302$ \\
Fire point $\left({ }^{\circ} \mathrm{C}\right)$ & ASTM D92 & 303 & $>302$ \\
Viscosity at & ASTM D4402 & 0.254 & - \\
$135^{\circ} \mathrm{C}(\mathrm{Pa} \cdot \mathrm{s})$ & & & - \\
Viscosity at & ASTM D4402 & 0.099 & - \\
$165^{\circ} \mathrm{C}(\mathrm{Pa} \cdot \mathrm{s})$ & ASTM D70 & 1.03 & - \\
Specific gravity & & & \\
\hline
\end{tabular}

the recycled concrete aggregates were soaked, washed, and dried well before being utilized in the asphalt mixture. The complete procedures to fabricate SMA specimens are described as follows.

(1) The required amount of aggregates (including RCA) and fillers were weighed and placed in oven at $200^{\circ} \mathrm{C}$ for 2 hours.

(2) To prevent binder drain down, the loose-form oil palm fibers $(0.3 \%$ by the weight of total mix) were used and mixed with the hot aggregates for a few seconds. 


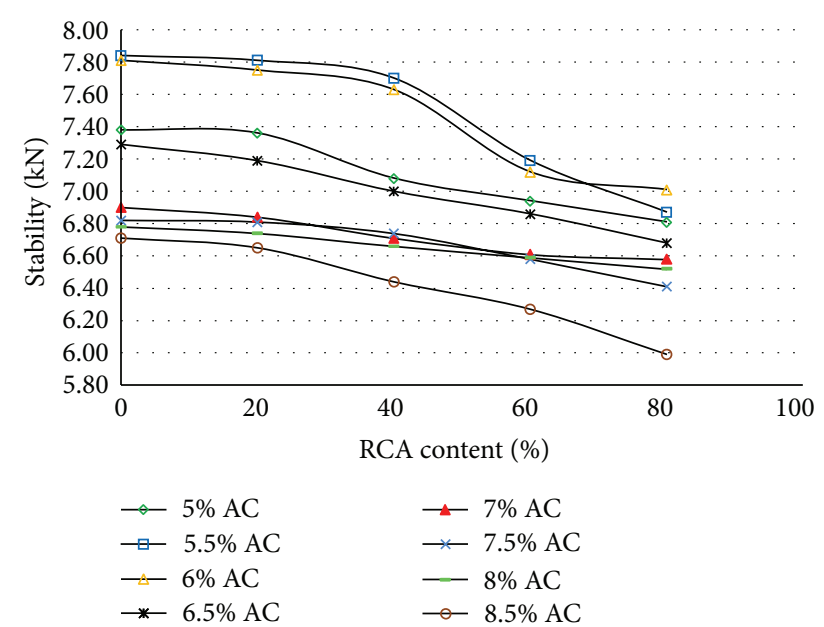

FIGURE 1: Marshall stability values versus RCA content for each percentage of asphalt content.

(3) The binder contents used in the asphalt mixtures were varied from 5 to $8.5 \%$ by the weight of the aggregates. The required quantity of $80 / 100$ binder was weighed and heated at $160^{\circ} \mathrm{C}$ for 1 hour. The binder was introduced to the aggregate mixture and mixing was carried out until all the aggregates were coated properly.

(4) The weighed amount of filler (hydrated limestone powder) was added at the end of the mixing procedure and mixed well for 5 minutes at $160^{\circ} \mathrm{C}$.

(5) The SMA mixtures were conditioned for 4 hours at $150^{\circ} \mathrm{C}$ and compacted at $145^{\circ} \mathrm{C}$ with Marshall compactor, giving 50 blows on each side of the mixture.

\section{Results and Discussion}

3.1. Marshall Stability. Figure 1 illustrated the Marshall stability (MS) values, including RCA for different percentages of binder contents. MS test was measured in accordance with ASTM D1559. Test results showed that the values of MS decreased with increasing the amount of RCA content in SMA mixtures. The slopes of the MS curves indicated that with $20 \%$ to $40 \%$ of RCA the MS values decreased slightly, but when the amount of RCA reached $40 \%$ and above the slopes are much steeper and MS values reduction was much more significant.

Based on the asphalt institute (AI) criteria, the stability value is expected to be higher than $750 \mathrm{lbs}$ or $3.4 \mathrm{KN}$ for medium traffic volumes. Test results revealed that the maximum level of MS value was $7.84 \mathrm{KN}$ for $5.5 \%$ binder and $0 \%$ RCA (100\% virgin aggregate mixture) and the minimum level was $5.99 \mathrm{KN}$ for $8.5 \%$ binder and $80 \% \mathrm{RCA}$. Therefore, all the specimens could fulfill the standard requirement. It is believed that, as the voids in SMA mixtures were filled with proper amounts of binder, the excessive asphalt content produced thicker bitumen films around the aggregates. Hence, the contacts between aggregates were considerably reduced,
TABLE 4: SMA specifications.

\begin{tabular}{lccc}
\hline Traffic & Light & Medium & Heavy \\
\hline $\begin{array}{l}\text { Compaction } \\
\text { (number of } \\
\text { blows) }\end{array}$ & 35 & 50 & 75 \\
Stability & Min 500 lb/ & Min 750 lb/ & Min 1400 lb/ \\
& $2224 \mathrm{~N}$ & $3336 \mathrm{~N}$ & $6227 \mathrm{~N}$ \\
Flow (0.25 mm) & Min 8-max & Min 8-max & Min 8-max \\
Air voids (\%) & 20 & 18 & 16 \\
VFA (\%) & Min 3-max 8 & Min 3-max 5 & Min 3-max 5 \\
& 75 & Min 65-max & Min 70-max \\
\hline
\end{tabular}

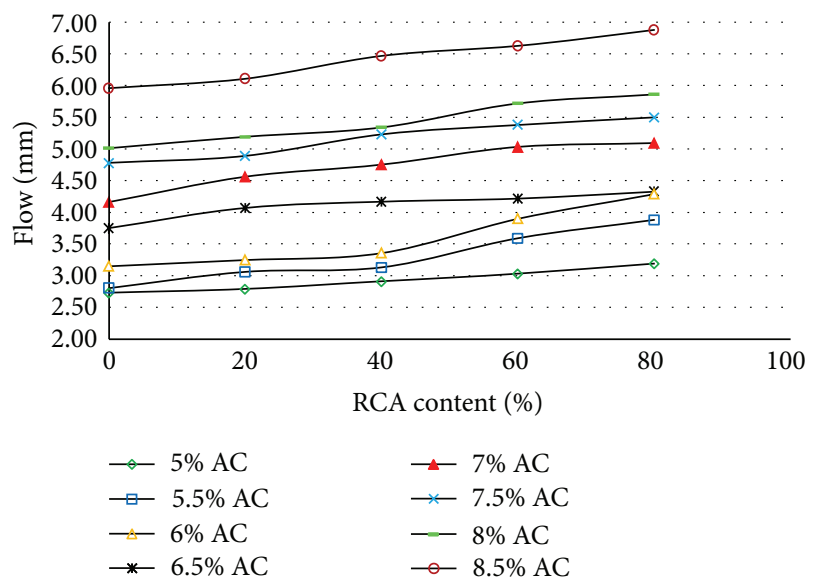

FIgURE 2: Marshall flow values versus RCA content for each percentage of asphalt content.

which leads to decrease in MS values with increasing RCA content. Table 4 presented the SMA specifications based on the asphalt institute.

3.2. Marshall Flow. Marshall flow is the vertical deformation of the asphalt specimen at the same time of running the Marshall stability (measured from start of loading, until the stability begins to decrease). The high value of flow shows high plasticity of the mix and will result in pavement rutting failure in the future. Also, the low value of flow might be as a result of high voids and insufficient binder, which may result in premature cracking in pavements [27]. Flow test was measured in accordance with ASTM D1559. Figure 2 displayed the flow values for different percentages of RCA in various binder levels. Test results indicated that as the RCA value increased the flow values increase as well. Based on the AI guideline for producing SMA mixtures, the optimum values for flow are between 2 to $4.5 \mathrm{~mm}$ for medium traffic volumes.

Test results revealed that the highest value of flow was $6.88 \mathrm{~mm}$ in the asphalt mixture including $80 \%$ of RCA and $8.5 \%$ binder content and the lowest flow was $2.73 \mathrm{~mm}$ in virgin aggregate mixtures with $5 \%$ of binder content. Therefore, the specimens containing 7, 7.5, 8 , and 8.5 asphalt 


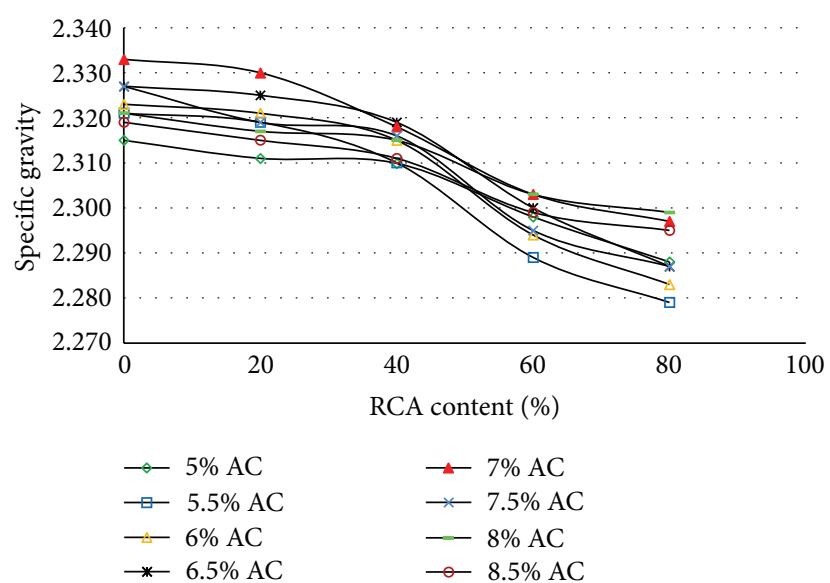

FIGURE 3: Specific gravity values versus RCA content for each percentage of asphalt content.

contents were not within the standard limits. It is believed that the higher porosity and absorption of RCA in comparison with the virgin granite aggregates caused the mentioned results. Moreover, the excessive binder content is another effective parameter on the flow of SMA specimens and as the percentage of binder raised in the asphalt mixtures the flow values increased accordingly.

3.3. Specific Gravity. Figure 3 presented the specific gravity values of SMA mixtures versus RCA content for different percentages of binders in accordance with ASTM D 118896. The specific gravity values of asphalt mixtures containing RCA were lower than the mixture including virgin aggregates. The lower values of specific gravity could be due to the lower specific gravity of concrete compared to granite aggregates. Hence, as the amount of RCA increased in asphalt mixtures, the specific gravity values decreased. The highest value of specific gravity was measured 2.333 for virgin aggregate $(0 \%$ RCA) mixture with $7 \%$ binder and the lowest value was 2.279 for mixture containing $80 \%$ RCA and $5.5 \%$ asphalt content.

3.4. Voids in Total Mix (VTM). Well-designed SMA pavements are expected to have enough air voids to prevent damage in the pavement under traffic and vehicle axle loads. Low air void levels cause the surface of the pavement to exhibit a brittle behavior which may lead to immature cracks, and high air void levels may present premature rutting, shoving, slippage, corrugation, or other pavement distresses. Therefore, the percentage of air voids must be sufficient and low enough to prevent permeability of air and water to the body of the pavement and high enough to prevent plastic flow after few years of opening to traffic [28]. The air voids in SMA specimens were measured in accordance with ASTM D320305. Figure 4 presented the VTM test results of the SMA mixtures containing various RCA and binder. The diagram showed that the voids in the total mix (VTM) values of different binder content are dependent on their relation with the RCA content and follow the same trend. As the amount of

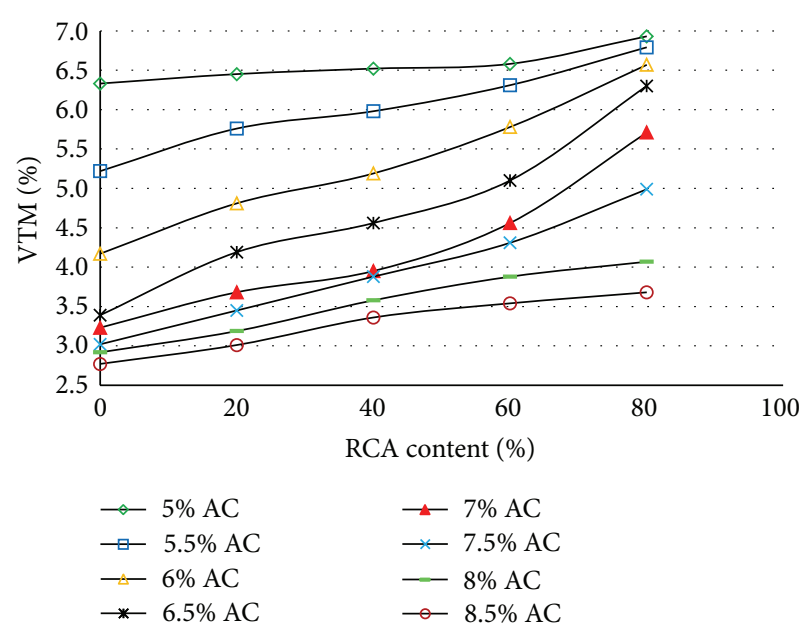

FIGURE 4: VTM values versus RCA content for each percentage of asphalt content.

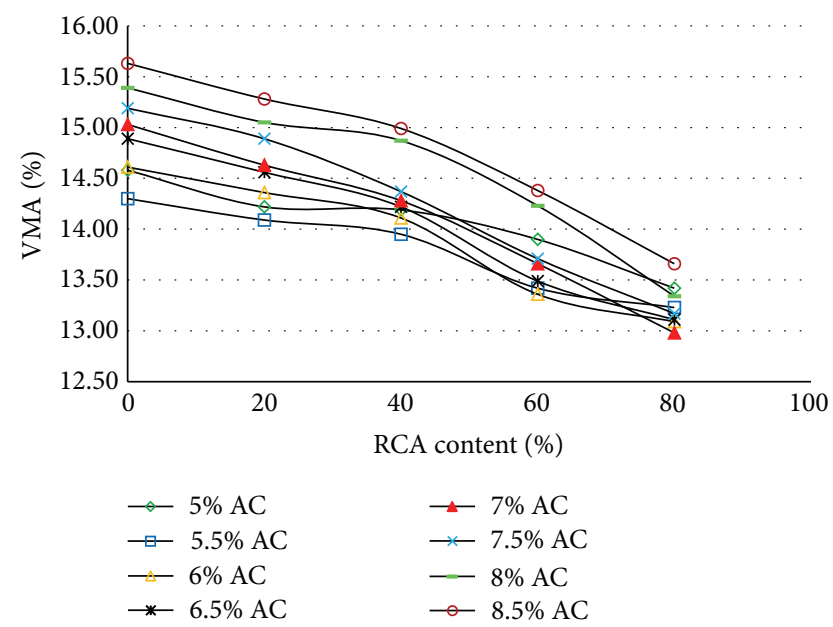

FIGURE 5: VMA values versus RCA content for each percentage of asphalt content.

RCA increased in SMA mixtures the VTM values increased as well.

The higher VTM values of SMA mixtures containing RCA are believed to be due to the higher porosity of concrete in comparison with virgin granite aggregates. Also, the air void levels cannot be controlled by Marshall compactor during the preparation of the SMA specimens. However, it is believed that the variation in terms of VTM levels in SMA mixtures containing RCA could be due to breaking down of the RCA during compaction. According to the AI, the optimum limits for air void values in compacted SMA specimens are between 3 to $5 \%$. However, based on the project requirements the VTM values can be changed as long as the other specifications have been met.

3.5. Voids in Mineral Aggregates (VMA). The voids in mineral aggregates (VMA) values versus RCA content for different percentages of binder content are presented in Figure 5. The 
TABLE 5: Minimum VMA requirement (based on nominal maximum aggregate size).

\begin{tabular}{lccc}
\hline \multirow{2}{*}{$\begin{array}{l}\text { Nominal maximum } \\
\text { aggregate size }(\mathrm{mm})\end{array}$} & \multicolumn{3}{c}{ Void in mineral aggregates (VMA) } \\
& $3 \%$ & $4 \%$ & $5 \%$ \\
\hline 2.36 & 19 & 20 & 21 \\
4.75 & 16 & 17 & 18 \\
9.50 & 14 & 15 & 16 \\
12.5 & 13 & 14 & 15 \\
19.0 & 12 & 13 & 14 \\
25.0 & 11 & 12 & 13 \\
37.5 & 10 & 11 & 12 \\
\hline
\end{tabular}

general trend of the graphs signified that as the percentages of RCA in SMA mixtures increased, the VMA decreased. The function of air voids and effective asphalt content in SMA mixtures affect the VMA values. Therefore, as the RCA content raised in the SMA mixtures, the binder absorption becomes higher and this incident reduced the effective binder content in asphalt mixtures which resulted in lower VMA values.

The maximum aggregate size in SMA 20 is $19 \mathrm{~mm}$ and the nominal maximum aggregate size is one sieve size below the maximum aggregate size which is $12.5 \mathrm{~mm}$. Based on $\mathrm{AI}$, the minimum value of VMA for the nominal maximum aggregate size of $12.5 \mathrm{~mm}$ at $4 \%$ design air voids is $14 \%$. Table 5 presented the minimum VMA requirement based on nominal maximum aggregate size.

3.6. Voids Filled with Asphalt (VFA). VFA is another factor to design a well-performing and durable asphalt mixture and known as the proportion of VMA which are filled with binder. Therefore, the values of effective binder content and VMA relate to each other. However, VMA and VFA values might be varied for different mixtures and are highly affected by aggregate gradation, quality of the materials, and compaction methods. Figure 6 displayed the measured VFA values for various percentages of RCA at different binder levels. Test results revealed that, regardless of the binder content, the VFA values of SMA specimens decreased with increasing RCA content.

It is believed that the higher degree of binder absorption in SMA mixtures (containing RCA) reduces the amount of effective binder in the asphalt mixtures. As the effective binder reduces, the VMA reduces and as the VMA decreases and the actual level of air voids in SMA specimens are not much fluctuated, the VFA performed like VMA and decreased as well. However, based on the SMA specification (Table 4) for the compacted specimens with 50 numbers of blows (medium traffic volume), the VFA values between 65 to 78 percent are within the acceptable range.

\section{Analysis of Variance (ANOVA)}

This paper reports the experimental test results on the feasibility of utilizing RCA in SMA mixtures and the effect

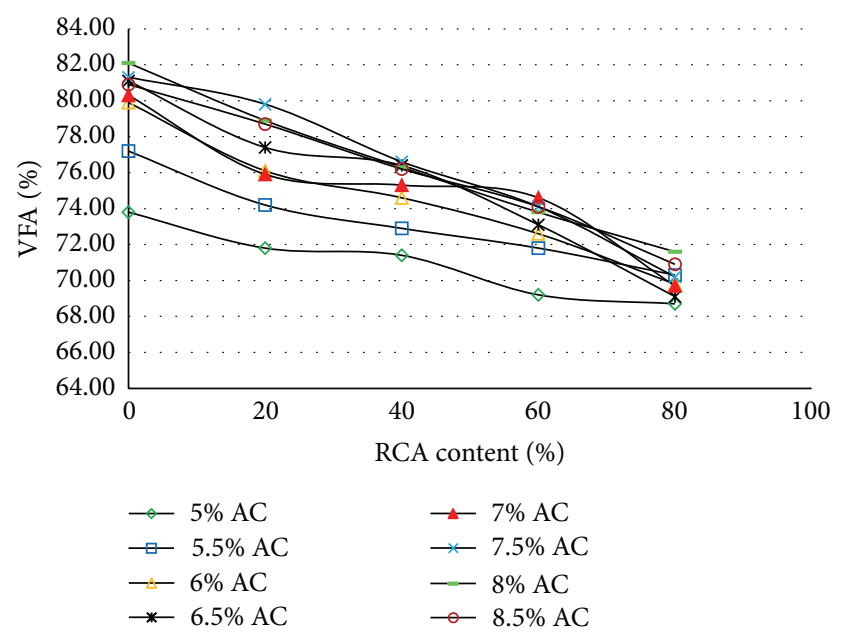

FIGURE 6: VFA values versus RCA content for each percentage of asphalt content.

of various percentages of RCA and binders on engineering properties of SMA specimens. However, to provide a better understanding of the role and effect of various RCA and binder content on the performance evaluation of the SMA specimens, all the test results were statistically analyzed using ANOVA. Prior to data analysis, all the data were subjected to normality and homogeneity tests. The results revealed that all the variances were homogenous and all the variables were distributed normally. Two-factor analysis of variance without replication was performed to evaluate the significance at certain confidence levels for research variables. Tables 6,7 , $8,9,10$, and 11 demonstrated the variance analysis of the outcomes.

The statistical analysis outcomes revealed that all the measured $P$ values were smaller than the significance level. In this research, the employed significance level $(\alpha)$ was assumed 0.05 . Moreover, the calculated values of $F$ were shown greater values in comparison with the values of $F$ criticalfor all the test results. Therefore, regarding to the above two fundamental presumptions, it can be concluded that the effect of various amounts of the RCA and binder was significant in the SMA mixtures.

\section{Conclusions}

This paper presented some of the experimental results obtained from utilization of recycled concrete aggregates (RCA) in stone mastic asphalt (SMA) mixtures. This section summarized the overall conclusions achieved through this research. The consequential findings of the current study are as follows.

(1) The bitumen absorption increased with increasing the RCA content in the SMA mixtures due to higher porosity of concrete and attached mortars on the surface of the crushed concretes. However, during the experiment, it was found that submerging the RCA in water and washing them before being used in the 
TABLE 6: Density test results (ANOVA: two-factor without replication).

\begin{tabular}{lcccccc}
\hline Source of variation & SS & df & MS & $F$ & $P$ value & $F$ critical \\
\hline Rows & 0.000688 & 7 & $9.82 E-05$ & 4.344972 & 0.002281 & 2.359259855 \\
Columns & 0.00702 & 4 & 0.001755 & 77.61635 & $9.73 E-15$ & 2.714075804 \\
Error & 0.000633 & 28 & $2.26 E-05$ & & \\
\hline Total & 0.008341 & 39 & & & \\
\hline
\end{tabular}

TABLE 7: Stability test results (ANOVA: two-factor without replication).

\begin{tabular}{lccccrr}
\hline Source of variation & SS & df & MS & $F$ & $P$ value & $F$ critical \\
\hline Rows & 5.388818 & 7 & 0.769831 & 52.02252 & $2.23 E-14$ & 2.359259855 \\
Columns & 1.970215 & 4 & 0.492554 & 33.28508 & $2.87 E-10$ & 2.714075804 \\
Error & 0.414345 & 28 & 0.014798 & & \\
\hline Total & 7.773378 & 39 & & & \\
\hline
\end{tabular}

TABLE 8: Flow test results (ANOVA: two-factor without replication).

\begin{tabular}{lccccrr}
\hline Source of variation & SS & df & MS & $F$ & $P$ value & $F$ critical \\
\hline Rows & 49.34183 & 7 & 7.048833 & 418.1334 & $1.36 E-26$ & 2.359259855 \\
Columns & 3.60126 & 4 & 0.900315 & 53.40625 & $1.05 E-12$ & 2.714075804 \\
Error & 0.47202 & 28 & 0.016858 & & \\
\hline Total & 53.41511 & 39 & & & \\
\hline
\end{tabular}

TABLE 9: VTM test results (ANOVA: two-factor without replication).

\begin{tabular}{lccccrr}
\hline Source of variation & SS & df & MS & $F$ & $P$ value & $F$ critical \\
\hline Rows & 48.91596 & 7 & 6.987994 & 67.26663 & $7.96 E-16$ & 2.359259855 \\
Columns & 14.24886 & 4 & 3.562215 & 34.28998 & $2.05 E-10$ & 2.714075804 \\
Error & 2.90878 & 28 & 0.103885 & & \\
\hline Total & 66.0736 & 39 & & & \\
\hline
\end{tabular}

TABLE 10: VMA test results (ANOVA: two-factor without replication).

\begin{tabular}{lcccccc}
\hline Source of variation & SS & df & MS & $F$ & $P$ value & $F$ critical \\
\hline Rows & 3.933938 & 7 & 0.561991 & 17.0107 & $1.49 E-08$ & 2.359259855 \\
Columns & 14.98899 & 4 & 3.747248 & 113.4241 & $7.13 E-17$ & 2.714075804 \\
Error & 0.92505 & 28 & 0.033038 & & \\
\hline Total & 19.84798 & 39 & & & \\
\hline
\end{tabular}

TABLE 11: VFA test results (ANOVA: two-factor without replication).

\begin{tabular}{|c|c|c|c|c|c|c|}
\hline Source of variation & SS & $\mathrm{df}$ & MS & $F$ & $P$ value & $F$ critical \\
\hline Rows & 124.4578 & 7 & 17.77968 & 15.70271 & $3.53 E-08$ & 2.359259855 \\
\hline Columns & 418.4765 & 4 & 104.6191 & 92.39786 & $1.03 E-15$ & 2.714075804 \\
\hline Error & 31.7035 & 28 & 1.132268 & & & \\
\hline Total & 574.6378 & 39 & & & & \\
\hline
\end{tabular}

asphalt mixtures considerably improved the performance of the RCA in SMA mixtures by reducing the binder absorption and increasing the adhesion between RCA and other materials in the mixtures.

(2) The amount of coarse aggregate (aggregates bigger than $2.36 \mathrm{~mm}$ ) was $76 \%$ based on the AI aggregate gradation (Table 1) for SMA, while this amount is close to $30 \%$ in conventional dense-graded (DG) mixtures. Therefore, the performance of the SMA mixtures is highly dependent on the specification of coarse aggregates (LA abrasion, aggregate impact value, and aggregate crushing value) compared to 
a conventional asphalt mixture, and any replacement of virgin aggregates with RCA has a significant effect on the engineering properties of the SMA.

(3) In this study RCA was combined with virgin granite as a mixture of fine and coarse by the weight of the total aggregates in the mixture. Regardless of the amount of RCA content in SMA mixtures, adding RCA to the asphalt mixtures significantly increase the VTM of the mixtures while decreasing its density values. The experimental results indicated that the SMA mixtures containing different percentages of RCA performed lower values in terms of density, stability, VMA, and VFA and higher values in terms of flow and air voids. This performance is believed to be due to higher porosity and lower specific gravity and density of the RCA compared to virgin aggregates.

(4) The volumetric and Marshall properties of SMA mixtures containing $20 \%$ and $40 \%$ RCA showed acceptable trends and could easily satisfy the standard requirements for medium traffic volumes. Nevertheless, SMA mixtures with more than 40\% RCA content is better to be used for low traffic pavements. However, more caution should be made on properties of asphalt mixtures with increasing the RCA content.

(5) In this research the unmodified 80/100 (penetration graded) binder was used for production of SMA specimens. However, using higher amounts of RCA in SMA mixtures containing modified binders should be considered in future investigation that is expected to perform better results compared to unmodified binders due to the higher durability and viscosity of modified binders.

\section{Conflict of Interests}

The authors declare that there is no conflict of interests regarding the publication of this paper.

\section{Acknowledgment}

The authors would like to acknowledge the institute of research management and monitoring (IPPP) of University of Malaya (UM) for the financial supports of this project (Project no. RP010A-13SUS).

\section{References}

[1] H. Akbulut and C. Gürer, "Use of aggregates produced from marble quarry waste in asphalt pavements," Building and Environment, vol. 42, no. 5, pp. 1921-1930, 2007.

[2] S. E. Zoorob and L. B. Suparma, "Laboratory design and investigation of the properties of continuously graded Asphaltic concrete containing recycled plastics aggregate replacement (Plastiphalt)," Cement and Concrete Composites, vol. 22, no. 4, pp. 233-242, 2000.

[3] Y. Huang, R. N. Bird, and O. Heidrich, "A review of the use of recycled solid waste materials in asphalt pavements," Resources, Conservation and Recycling, vol. 52, no. 1, pp. 58-73, 2007.
[4] K. Rahal, "Mechanical properties of concrete with recycled coarse aggregate," Building and Environment, vol. 42, no. 1, pp. 407-415, 2007.

[5] F. Agrela, M. S. de Juan, J. Ayuso, V. L. Geraldes, and J. R. Jiménez, "Limiting properties in the characterisation of mixed recycled aggregates for use in the manufacture of concrete," Construction and Building Materials, vol. 25, no. 10, pp. 39503955, 2011.

[6] B. Mas, A. Cladera, T. D. Olmo, and F. Pitarch, "Influence of the amount of mixed recycled aggregates on the properties of concrete for non-structural use," Construction and Building Materials, vol. 27, no. 1, pp. 612-622, 2012.

[7] V. Spaeth and A. D. Tegguer, "Improvement of recycled concrete aggregate properties by polymer treatments," International Journal of Sustainable Built Environment, vol. 2, no. 1, pp. 143-152, 2013.

[8] E. Vázquez, M. Barra, D. Aponte, C. Jiménez, and S. Valls, "Improvement of the durability of concrete with recycled aggregates in chloride exposed environment," Construction and Building Materials, vol. 67, pp. 61-67, 2014.

[9] F. D. C. Leite, R. D. S. Motta, K. L. Vasconcelos, and L. Bernucci, "Laboratory evaluation of recycled construction and demolition waste for pavements," Construction and Building Materials, vol. 25, no. 6, pp. 2972-2979, 2011.

[10] D. X. Xuan, L. J. M. Houben, A. A. A. Molenaar, and S. Zhonghe, "Cement treated recycled demolition waste as a road base material," Journal of Wuhan University Technology-Materials Science, vol. 25, no. 4, pp. 696-699, 2010.

[11] A. R. Pasandín and I. Pérez, "Mechanical properties of hotmix asphalt made with recycled concrete aggregates coated with bitumen emulsion," Construction and Building Materials, vol. 55, no. 31, pp. 350-358, 2014.

[12] C. S. Poon and D. Chan, "Feasible use of recycled concrete aggregates and crushed clay brick as unbound road sub-base," Construction and Building Materials, vol. 20, no. 8, pp. 578-585, 2006.

[13] Y. D. Wong, D. D. Sun, and D. Lai, "Value-added utilisation of recycled concrete in hot-mix asphalt," Waste Management, vol. 27, no. 2, pp. 294-301, 2007.

[14] J. Mills-Beale and Z. You, "The mechanical properties of asphalt mixtures with recycled concrete aggregates," Construction and Building Materials, vol. 24, no. 3, pp. 230-235, 2010.

[15] S. Paranavithana and A. Mohajerani, "Effects of recycled concrete aggregates on properties of asphalt concrete," Resources, Conservation and Recycling, vol. 48, no. 1, pp. 1-12, 2006.

[16] M. Arabani, F. Moghadasnejad, and A. R. Azarhoosh, "Laboratory evaluation of recycled waste concrete into asphalt mixtures," International Journal of Pavement Engineering, vol. 14, no. 6, pp. 531-539, 2013.

[17] M. Arabani and A. R. Azarhoosh, "The effect of recycled concrete aggregate and steel slag on the dynamic properties of asphalt mixtures," Construction and Building Materials, vol. 35, pp. 1-7, 2012.

[18] S. Wu, J. Zhong, J. Zhu, and D. Wang, "Influence of demolition waste used as recycled aggregate on performance of asphalt mixture," Road Materials and Pavement Design, vol. 14, no. 3, pp. 679-688, 2013.

[19] C.-H. Lee, J.-C. Du, and D.-H. Shen, "Evaluation of pre-coated recycled concrete aggregate for hot mix asphalt," Construction and Building Materials, vol. 28, no. 1, pp. 66-71, 2012. 
[20] M. J. Chen and Y. D. Wong, "Porous asphalt mixture with $100 \%$ recycled concrete aggregate," Road Materials and Pavement Design, vol. 14, no. 4, pp. 921-932, 2013.

[21] A. R. Pasandín and I. Pérez, "Effect of ageing time on properties of hot-mix asphalt containing recycled concrete aggregates," Construction and Building Materials, vol. 52, pp. 284-293, 2014.

[22] W. A. Gul and M. Guler, "Rutting susceptibility of asphalt concrete with recycled concrete aggregate using revised Marshall procedure," Construction and Building Materials, vol. 55, no. 1, pp. 341-349, 2014.

[23] I. Pérez, A. R. Pasandín, and L. Medina, "Hot mix asphalt using C\&D waste as coarse aggregates," Materials and Design, vol. 36, pp. 840-846, 2012.

[24] Y.-H. Cho, T. Yun, I. T. Kim, and N. R. Choi, "The application of recycled concrete aggregate (RCA) for hot mix asphalt (HMA) base layer aggregate," KSCE Journal of Civil Engineering, vol. 15, no. 3, pp. 473-478, 2011.

[25] D. X. Xuan, L. J. M. Houben, A. A. A. Molenaar, and Z. H. Shui, "Mixture optimization of cement treated demolition waste with recycled masonry and concrete," Materials and Structures, vol. 45, no. 1-2, pp. 143-151, 2012.

[26] M. S. Pourtahmasb and M. R. Karim, "Performance evaluation of stone mastic asphalt and hot mix asphalt mixtures containing recycled concrete aggregate," Advances in Materials Science and Engineering, vol. 2014, Article ID 863148, 12 pages, 2014.

[27] E. R. Brown, "Density of asphalt concrete-how much is needed?" NCAT Research Report 90-3, Annual Meeting of the Transportation Research Board, Washington, DC, USA, 1990.

[28] M. M. Rafi, A. Qadir, and S. H. Siddiqui, "Experimental testing of hot mix asphalt mixture made of recycled aggregates," Waste Management and Research, vol. 29, no. 12, pp. 1316-1326, 2011. 

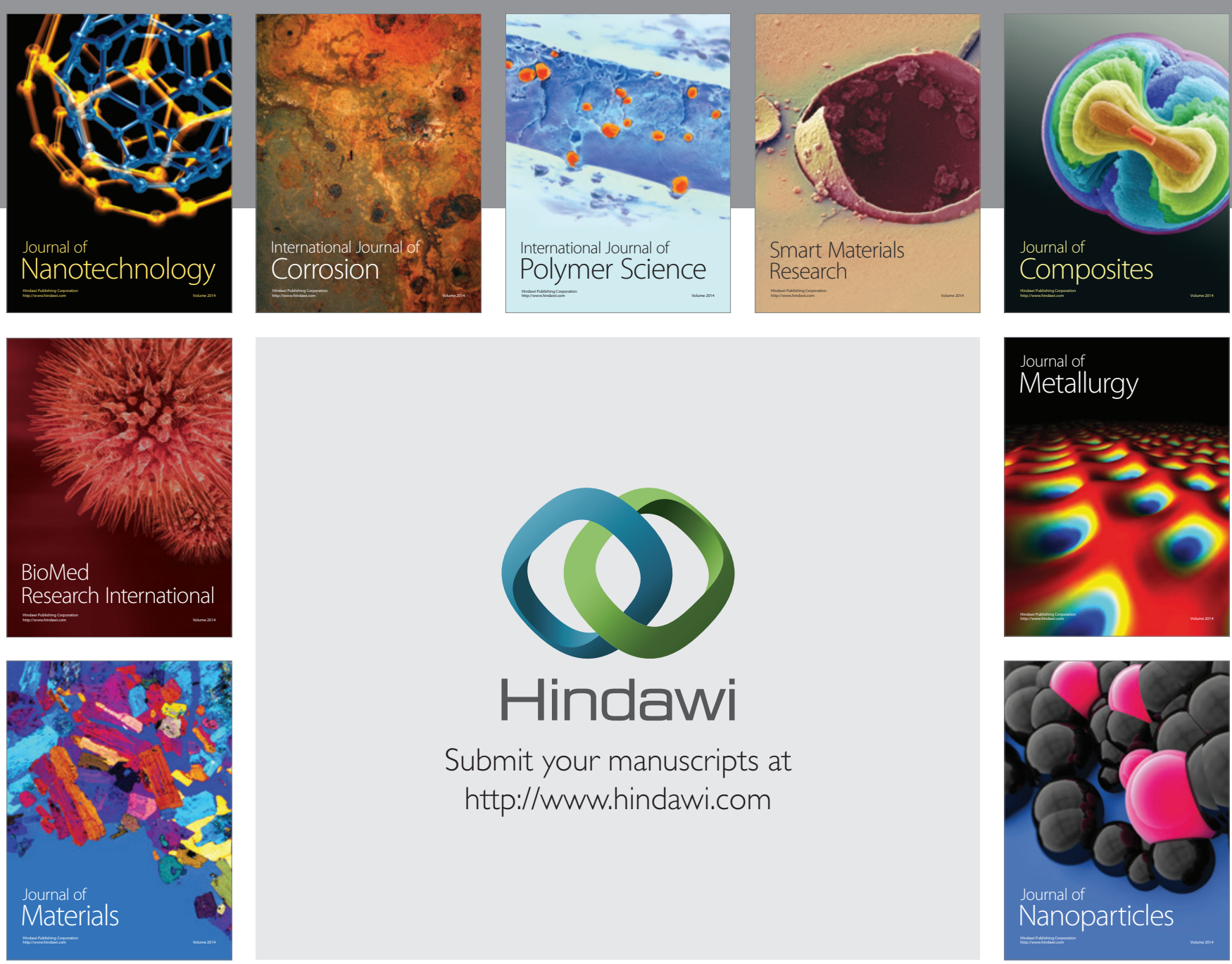

Submit your manuscripts at http://www.hindawi.com
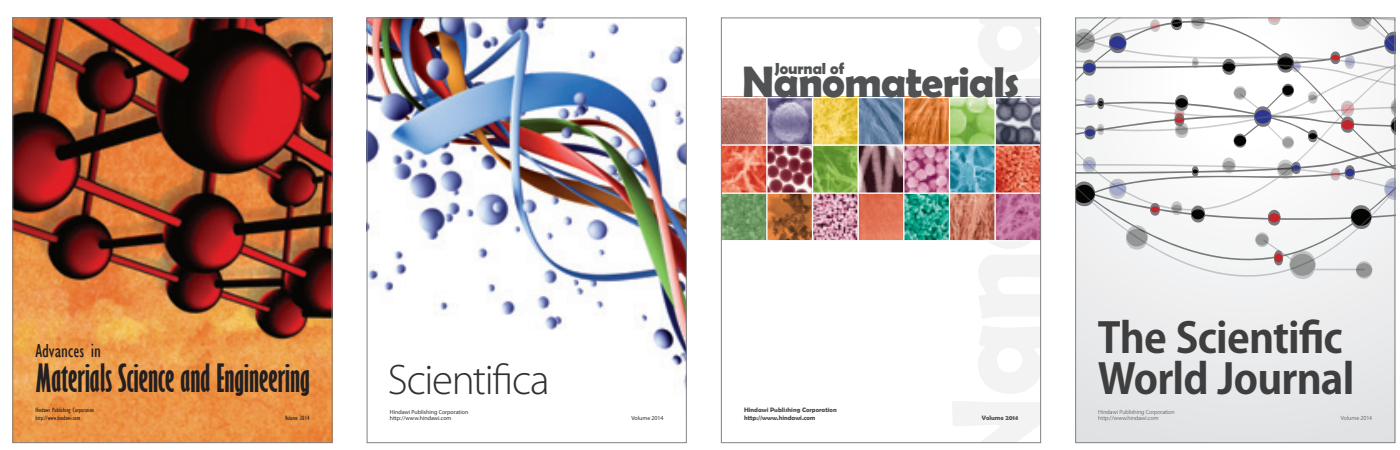

\section{The Scientific World Journal}
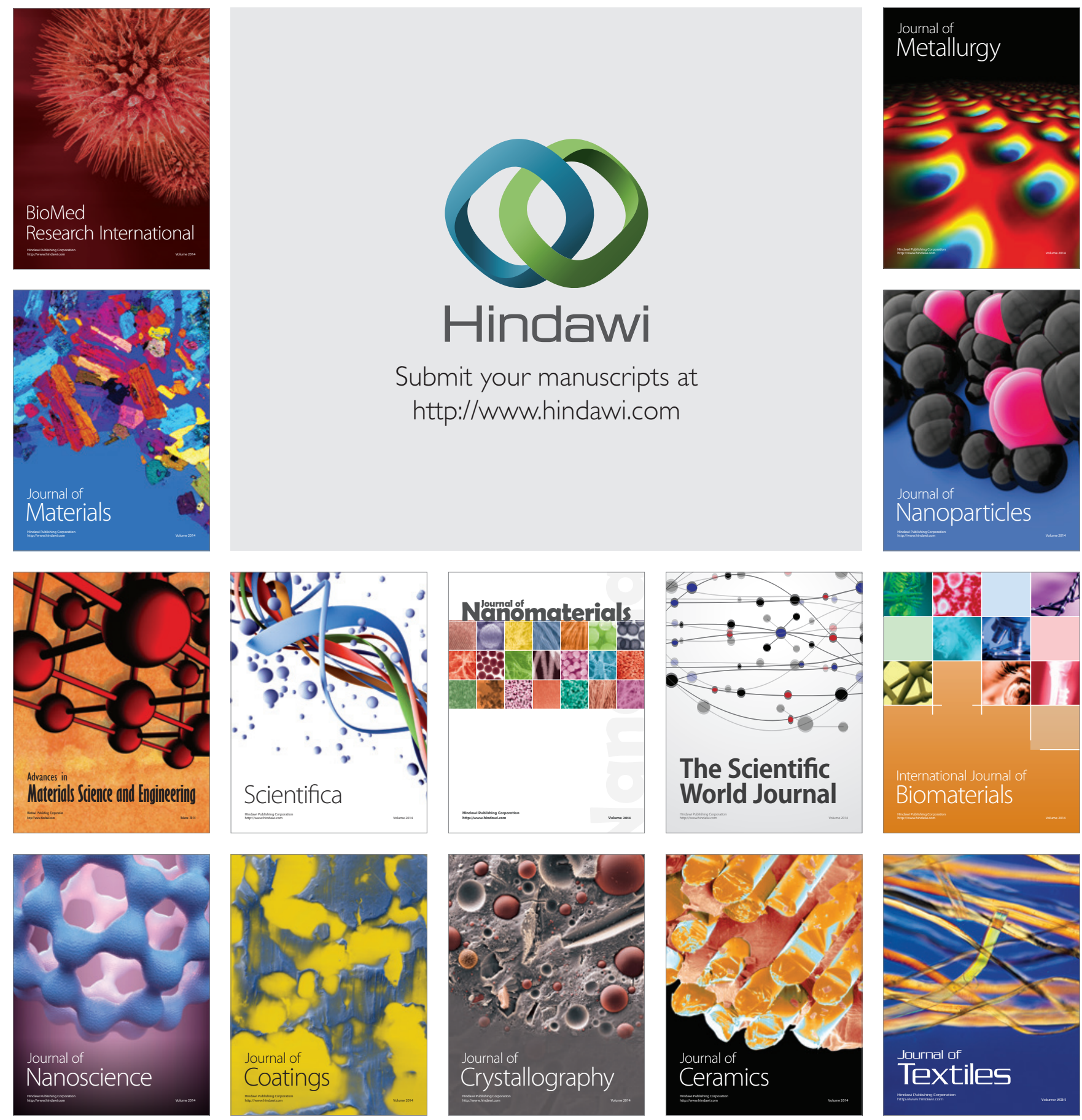